\title{
Demographic and autopsy characteristics of drowning deaths in a major autopsy center of Gandaki province of Nepal
}

\author{
Madan Prasad Baral ${ }^{1 *}$ (iD), Nuwadatta Subedi ${ }^{2}$ \\ 'Department of Forensic Medicine, Pokhara Academy of Health Sciences, Western Regional Hospital, Pokhara, Nepal, \\ ²Department of Forensic Medicine, Gandaki Medical College, Pokhara, Nepal
}

\begin{abstract}
Background: Autopsy examination is mandatory in all unnatural deaths as per law of Nepal and thus all deaths due to drowning are undergone medico legal autopsy. This study aims to analyze the demographic and autopsy characteristics of drowning deaths in cases brought for medico legal autopsy at a major autopsy center of Gandaki province of Nepal. Methods: This study was conducted based on review of database in a period of two years among 53 corpses of drowning related deaths. The demographic data and relevant information from the inquest and autopsy report of such cases were collected and presented. Result: The commonest age group involved in drowning deaths was $<20$ years, attributing to $22(41.5 \%)$ cases, and with males $(41,77.4 \%)$ more common than females. Suicidal drowning $(34,64.2 \%)$ was the commonest manner. Maximum (19, 35.8\%) deaths occurred in the rainy season and on lakes (34, 64.1\%). Conclusion: Drowning deaths were more common among males of young age groups. Most of the drownings occurred during the rainy season, lakes were the common sites of drowning, and the commonest manner was suicidal.
\end{abstract}

Keywords: Autopsy, drowning, medico legal,

\section{*Correspondence:}

Dr. Madan Prasad Baral

Assistant Professor

Department of Forensic Medicine Pokhara Academy of Health Sciences, Western Regional Hospital, Pokhara, Nepal

Email: madanprasadbaral@gmail.com

Submitted: January 24, 2021

Accepted: June 23, 2021

To cite: Baral MP, Subedi N. Demographic and autopsy characteristics of drowning deaths in a major autopsy center of Gandaki province of Nepal. JGMC Nepal. 2021;14(1):50-3.

DOI: $10.3126 /$ jgmcn.v14i1.32661

\section{INTRODUCTION}

In worldwide scenario, drowning is the third leading cause of unintentional injury death, and accounts for $7 \%$ of all injury-related deaths. Annually there are nearby 236,000 drowning deaths globally. This global estimate may significantly undervalue the actual public health problem regarding drowning deaths. Children, males, and persons with increased contact to water are at highest risk of drowning. ${ }^{1}$

Pokhara is the metropolitan city of Kaski district in the Gandaki Province of Nepal. It is the second largest city of Nepal after Kathmandu and the most beautiful city in Nepal. There are seven lakes present in Pokhara valley ${ }^{2}$ and several rivers, dams, canals etc. in and around Kaski district. So, the drowning deaths are also commonly presented from this region. Drowning can be defined as death due to submersion in liquid. ${ }^{3}$ It is a form of asphyxia due to aspiration of fluid into air- passages, caused by submersion in water or other fluid. ${ }^{4}$ Death can occur in an ocean or water as shallow as $15 \mathrm{~cm}$ in the case of alcoholic stupor, epileptics, or infants. ${ }^{3} \mathrm{~A}$ report from Bangladesh showed the fatal drowning rate to be as high as 15.8 per 100,000 population. ${ }^{5}$ There have been several studies at a sub-national level examining non-fatal drowning in Australia. Wallis et $\mathrm{al}^{6}$ mapped mortality and morbidity rates among children and adolescents of 0 to 19 years in Queensland. The literature of drowning related deaths 
in Nepal is sparse.

Drowning can occur in any lakes and other water resources due to an accident, Suicide and rarely homicide as well. Medico legal aspects of drowning related research is rarely conducted earlier in this region. The main aim of this study is to analyze the demographic profile related to medico legal aspects of drowning death and related autopsy characteristics.

\section{METHODS}

This was a hospital databased cross sectional descriptive study conducted at central level hospital of Nepal. The study duration was from July to December 2019. All the available autopsy records of drowning cases of in a period of two years from January 1, 2017, to December 31,2019 , were reviewed. Cases with history of drowning as mentioned in the inquest report and with suggestive of drowning from internal and external autopsy findings were included in this study. The cases other than drowning, corpse with history of drowning but in an advance stage of decomposition where drowning was not diagnosed from autopsy and those cases with incomplete data were excluded.

The data was collected in a structured proforma designed for the study. It consisted of the demographic information of the cases. The manner of death was classified as accidental, suicidal, homicidal, and undetermined based on the inquest report and autopsy findings. The site of drowning was classified based on the place where the body was retrieved, and the season of death according to the six categories in Nepalese context.

The permission to conduct the study was obtained from hospital management and ethical approval from the Pokhara Academy of Health Sciences. Privacy of data was maintained while collecting and presenting the data. The obtained data was entered and analyzed in Microsoft excel and presented in frequency and percentage.

\section{RESULTS}

Table 1: Distribution of cases with respect to age and sex

\begin{tabular}{cccc}
\hline $\begin{array}{c}\text { Age Group } \\
\text { (years) }\end{array}$ & $\begin{array}{c}\text { Male (n=41) } \\
\text { Frequency (\%) }\end{array}$ & $\begin{array}{c}\text { Female (n=12) } \\
\text { Frequency (\%) }\end{array}$ & $\begin{array}{c}\text { Total (N=53) } \\
\text { Frequency (\%) }\end{array}$ \\
$<20$ & $16(39.0)$ & $6(50.0)$ & $22(41.5)$ \\
$20-40$ & $14(34.1)$ & $3(25.0)$ & $17(32.1)$ \\
$40-60$ & $6(14.6)$ & $3(25.0)$ & $9(17.0)$ \\
$60-80$ & $4(9.8)$ & $0(0)$ & $4(7.5)$ \\
$>80$ & $1(2.4)$ & $0(0)$ & $1(1.9)$ \\
\hline
\end{tabular}

We observed that occurrence of drowning was more in age group of $<20$ years accounting to $22(41.5 \%)$ cases whereas it was least in old age at $>80$ years with only one case in the group. (table 1) When observing sex wise distribution of cases, we found that there was male predominance over the females in drowning cases with 41 (77.4\%) males and $12(28.3 \%)$ females out of total 53 cases. It was found that $30(56.6 \%)$ were married and $23(43.4 \%)$ unmarried persons. When we compared the manner of deaths, it was found that the suicidal drowning cases $(34,64.2 \%)$ were higher in number which was followed by accidental $(15$, $28.3 \%$ ) drowning deaths. In four (7.5\%) cases, the manner was not determined. There were no cases of homicidal drowning. The distribution of manner of deaths in drowning is shown in table 2.

Table 2: Manner wise distribution of cases

\begin{tabular}{ccc}
\hline Manner & Number & Percentage \\
Suicidal & 34 & 64.2 \\
Accidental & 15 & 28.3 \\
Undetermined & 04 & 7.5 \\
Total & 53 & 100.0 \\
\hline
\end{tabular}

Table 3: Distribution of cases with respect to religion

\begin{tabular}{ccc}
\hline Religion & Number & Percentage \\
Hindu & 33 & 62.3 \\
Buddhist & 11 & 20.7 \\
Christian & 6 & 11.3 \\
Muslim & 2 & 3.7 \\
Others & 1 & 1.9 \\
Total & 53 & 100.0 \\
\hline
\end{tabular}

Table 4: Site of drowning of cases

\begin{tabular}{ccc}
\hline Site & Number & Percentage \\
Lake & 34 & 64.1 \\
River & 8 & 15.1 \\
Canal & 6 & 11.3 \\
Water tank & 3 & 5.7 \\
Pond & 1 & 1.9 \\
Swimming pool & 1 & 1.9 \\
Total & 53 & 100.0 \\
\hline
\end{tabular}

The distribution of religion in the study cases is shown in table 3. Hindus were the commonly involved with 33 (62.3\%) cases followed by Buddhists with 11 (20.7\%). In our observation, most of the drowning occurred in lakes $(34,64.1)$, followed by river in eight $(15.1 \%)$ and canals in six $(11.3 \%)$ cases. The distribution of site of drowning 
is presented in table 4 . As shown in table 5 , most of the drowning occurred in rainy season $(19,35.8 \%)$ followed by summer season in $10(18.9 \%)$ cases.

Table 5: Distribution of cases with respect to season

\begin{tabular}{ccc}
\hline Season & Number & Percentage \\
Spring & 3 & 5.7 \\
Summer & 10 & 18.9 \\
Rainy & 19 & 35.8 \\
Autumn & 4 & 7.5 \\
Prewinter & 8 & 15.1 \\
Winter & 9 & 16.9 \\
Total & 53 & 100.0 \\
\hline
\end{tabular}

\section{DISCUSSION}

This study presents the demographic and autopsy characteristics of drowning deaths among cases brought for medico legal autopsy in a major autopsy center of Gandaki province of Nepal. In our observation, we found that the victims of drowning are more within the age group of 20 years. The distribution is almost similar with the study conducted by the Sedain et al. ${ }^{7}$ and Nayak et al. ${ }^{14}$ in which they observed younger people ( $<20$ years) with involvement of more than half of the total drowning deaths. The observation is also in accordance with that presented by others. ${ }^{7,10-12}$ Rahman et al. ${ }^{5}$ mentioned maximum number of drowning in age group of more than 25 years which are slightly higher than the current study.

Males outnumbered females in our study, and this is in accordance with the findings presented by Rao et al. ${ }^{8}$ in Kakinada, Andhra Pradesh India. Pal et al. ${ }^{9}$ also have presented similar findings with male predominance (75.755) in drowning, Likewise, Phad et al. ${ }^{10}$ in their study done in central India explored $72.02 \%$ victims were males and $28.98 \%$ were female, with ratio $2.45: 1$. Saunders et al. ${ }^{11}$ found drowning rates were four-fold higher in men compared with women. Kumar et al. $^{12}$ found that the maximum drowning cases were of male sex. The male preponderance can be explained by the fact that males are mostly involved in outdoor activities, have higher chances of taking risk and travel more. Rahman et al. ${ }^{5}$ in Bangladesh found that drowning deaths are predominant in females $(51.46 \%)$ over male and contrary to current study. This finding could be due to different population distribution in their settings or the differences in roles of both the gender.

We noticed suicide was the commonest manner of drowning and it was followed by accidental which is similar with the study conducted by Pal et al ${ }^{9}$ Kumar et al. ${ }^{12}$ Nayak et al. ${ }^{13}$ found the accidental drowning cases are more than that of suicidal which is contrary to the current study. In our study, deaths due to drowning was comparatively more in the married than that of unmarried person and the findings are almost consistent with the study conducted by Pal et al. ${ }^{9}$ and Phad et al. ${ }^{10}$

It was found that religion status is not mentioned in various drowning death cases and data with such study is very rare. In our study, we found the maximum number of drowning cases are in the order of Hindu followed by Buddhist, Muslim, Christian and others. The distribution of religion in our context is consistent with the population distribution of religion in our province.

In our observation, maximum number of cases of drowning occurred at lakes, followed by river and canal. The findings are almost consistent with findings presented by Nayak et al. ${ }^{13}$ and Phad et al. ${ }^{10}$ Pal et al. ${ }^{9}$ found highest number of persons drowned in river and Rahman et al. ${ }^{11}$ found in pond. Kumar et al. ${ }^{12}$ found the maximum number in water canal. Peden et al. ${ }^{14}$ found that drowning is more likely to be fatal among older people and in natural waterways such as rivers, lakes, beaches, and oceans of Australia. As the Kaski district is the reservoir of several lakes and the Gandaki province has several large rivers, the sites of drowning are explainable.

In the present study, the maximum cases of drowning occurred in a Rainy (mid-July to mid-September) followed by summer (mid-May to mid-July) season. This is almost consistent with another study conducted by Sedain et $\mathrm{al}^{7}$ in Nepal, Rao et al. ${ }^{8}$ in Andhra Pradesh India, Pal et al. ${ }^{9}$ in Himanchal Pradesh India, Phad et al. ${ }^{10}$ in central India, Rahman et al. ${ }^{5}$ in Bangladesh, but contrasts with the study conducted by Peden et al. ${ }^{14}$ in Australia. There are unpredictable floods in the rainy season, water levels in ponds and rivers are high contributing to higher number of drowning during the rainy season. As well, people also accidentally drown in the ditches filled with water at occasions.

Drowning deaths are one of the neglected issues in our context. Mostly, young people of productive age groups die due to drowning. It could be attributed to the lack of safety guidelines, open ditches and canals and lack of restrictions to go to the lakes and rivers. Particularly in the rainy seasons, the risk of drowning increases because of the same reasons. At times, people also take risks to cross rivers and canals in the absence of bridges. The young people have tendency to take risks to swim in rivers and 
lakes with unpredictable risks. The concerned authorities should take the issue seriously to prevent drowning related deaths and develop awareness campaigns, build safety measures, and develop guidelines to use water reservoirs.

Limitation: This study is conducted in a single center and could not have totally represented the profile of drowning deaths of the province. As this is a record review, we could not present holistic demographic and autopsy profile of cases.

\section{CONCLUSION}

Drowning deaths were more common among males of young age groups. Most of the drownings occurred during the rainy season, lakes were the common sites of drowning, and the commonest manner was suicidal. Preventive measures and awareness campaigns are essential to prevent drowning deaths which takes life of the productive age group people of the nation.

\section{Conflicts of Interest: None}

\section{REFERENCES}

1. World Health Organization. Drowning key facts. Available from: https://www.who.int/news-room/fact-sheets/detail/drowning. [Accessed 11th February 2020]

2. Li L, Xia H, Li Z, Zhang Z. Temporal-Spatial Evolution Analysis of Lake Size-Distribution in the Middle and Lower Yangtze River Basin Using Landsat Imagery Data. Remote Sens. 2015;7(8):10364-84. DOI:10.3390/rs70810364

3. Modi JP. A Textbook of Medical Jurisprudence and Toxicology. Lexis Nexis; 2012.

4. Reddy KSN. The Essentials of Forensic Medicine and Toxicology. Jaypee the health sciences publishers; 2014.

5. Rahman A, Alonge O, Bhuiyan AA, Agrawal P, Salam S, Talab A, et al. Epidemiology of Drowning in Bangladesh: An Update. International Journal of Environmental Research and Public Health [Internet]. MDPI AG; 2017 May 5;14(5):488.
DOI:10.3390/ijerph14050488

6. Wallis BA, Watt K, Franklin RC, Nixon JW, Kimble RM. Drowning Mortality and Morbidity Rates in Children and Adolescents 0-19yrs: A Population-Based Study in Queensland, Australia. PLoS One. 2015 Feb 25;10(2):e0117948. DOI:10.1371/journal.pone.0117948

7. Sedain B, Pant PR. Status of drowning in Nepal: A study of central police data. F1000Res. 2018 May 14;7:576. DOI:10.12688/f1000 research.14563.2

8. Rao R, Surendar J, Prasad GKV. A Comprehensive Study of Drowning in and around Kakinada, Two years Retrospective Study. Scholars Journal of applied medical Sciences. 2014;2(4D):1397-401.

9. Pal SK, Sharma A, Sehgal A, Rana A. Diagnosing death with diatoms: A retrospective study of forensic cases in Himachal Pradesh, India. International Journal of Medical Toxicology and Forensic Medicine. 2017;7(2):124-37. DOI:10.22037/ ijmtfm.v7i2(Spring).16373

10. Phad LG, Dhawane SG. Epidemiological profile of drowning deaths: a cross sectional study. Egypt J Forensic Sci. 2018;8(1). DOI:10.1186/s41935-018-0056-8

11. Saunders CJ, Adriaanse R, Simons A, van Niekerk A. Fatal drowning in the Western Cape, South Africa: a 7-year retrospective, epidemiological study. Inj Prev. 2019;25(6):52934. DOI: 10.1136/injuryprev-2018-042945

12. Kumar A, Sharma L, Kumar B. Profile of medico-legal deaths due to drowning - a retrospective study. IJSR. 2019;1-2. DOI:10.36106/ijsr

13. Nayak GH, Karlawad M, Biradar SKS. A medicolegal examination of drowning deaths-A retrospective study. Med-leg update. 2017;17(2):104. DOI:10.5958/09741283.2017.00079.2

14. Peden AE, Mahony AJ, Barnsley PD, Scarr J. Understanding the full burden of drowning: a retrospective, cross-sectional analysis of fatal and non-fatal drowning in Australia. BMJ Open. 2018;8(11):e024868. DOI:10.1136/bmjopen-2018-024868 